\title{
THE INDIVIDUAL 'COSTS’ OF WORKAHOLISM: AN ANALYSIS BASED ON MULTISOURCE AND PROSPECTIVE DATA
}

\begin{abstract}
We conducted two studies on workaholism to address three identified gaps in the literature (Clark et al., 2014), namely, the job-related affective experiences of workaholics, the relationship between workaholism and job demands, and the long-term mental health effects of workaholism. We also examined gender as a moderator of the relationship between workaholism and its outcomes. In Study $1(N=311)$, focused on a heterogeneous sample of workers, we found that workaholism was positively related to the experience of observer-reported, as well as self-reported, job-related negative affect and that this relationship was stronger among female workers. Furthermore, in a subsample of participants $(N=189)$ for whom we had available blood pressure data, we found that workaholism was positively related to systolic blood pressure. In Study $2(N=235)$, based on a sample of health-sector employees in which we adopted a full, two-wave panel design including workaholism, job demands, and psychological distress, we found that the baseline levels of job demands impacted the follow-up levels of workaholism, while the reverse was not the case. We also found that the baseline levels of workaholism positively affected the levels of mental distress reported after one year. These results add to the existing literature on the job-related affective correlates and psychophysical costs of workaholism and shedding further light on work environmental factors that may contribute to its genesis.
\end{abstract}

Keywords: workaholism; work addiction; work-related stress; blood pressure; multisource study 


\section{THE INDIVIDUAL 'COSTS' OF WORKAHOLISM: AN ANALYSIS BASED ON MULTISOURCE AND PROSPECTIVE DATA}

In recent years, increasing attention has been paid to the phenomenon of work addiction or workaholism, which was first defined by Oates (1971) as an irresistible or uncontrollable need to work incessantly. Such interest may also be explained in light of the changes that characterize modern working life (Naswall, Hellgren, \& Sverke, 2008), with workers being increasingly exposed to an intensified workload and demands for flexibility, initiative-taking, planning and decisionmaking, and continuous learning. In brief, conditions that may lead to a heavy work investment are becoming more prevalent, not only for managerial jobs. Furthermore, according to some (e.g., Cunningham, De La Rosa, \& Jex, 2008), in this dynamic context personal characteristics will become more important in understanding individual adaptation to work, and thus for well-being and performance. Workaholism may be one such personal characteristic.

Since the initial clinical observations of the workaholism phenomenon (see Lowman, 1993), scientific research has grown considerably in the past decade focused on refining the workaholism construct (Ng, Sorensen, \& Feldman, 2007; Snir \& Harpaz, 2012). However, there is a clear need for more rigorous research that addresses existing methodological and substantive gaps in the available literature. A recent meta-analysis (Clark, Michel, Zhdanova, Pui, \& Baltes, 2014) highlighted a number of open research issues on workaholism. One of these issues is the prevailing quality of the job-related affective experiences of workaholics, an issue with critical implications for the definition of the phenomenon. According to some ( $\mathrm{Ng}$ et al., 2007; Baruch, 2011) workaholics work hard because they enjoy their work. However, the repeated finding of a relationship between workaholism and job stress and burnout raises some doubts on this and suggests that workaholics may frequently experience negative affect (e.g., tension and anxiety) not only when not working, but also when they work. A further issue regards the role of external pressures on workaholic behavior. Although the available research (e.g., Robinson \& Kelley, 1998) 
seems to indicate that workaholism is a fairly stable personal characteristic, the impact of situational factors such as high job demands on workaholic tendencies has never been addressed adequately. A third issue concerns the health consequences of workaholism. While there is an abundance of evidence for a relationship between workaholism and health and well-being outcomes (e.g. Schaufeli, Bakker, van der Heijden, \& Prins, 2009) such evidence is almost exclusively based on cross-sectional, self-report studies, meaning that clear cause-effect analyses are still scarce, and reverse causation or important third factors such as negative affectivity may not be excluded as explanations. This limitation has been emphasized by Clark et al. (2014), who called for the use of more sophisticated research designs in this area. Finally, investigations on moderators of the workaholism-outcomes relationships - which would yield a more fine-grained understanding of the potential effects of workaholism - are also lacking.

In the two studies reported here we advance workaholism research by concentrating on the issues introduced above (Clark et al., 2014): namely, the quality of the job-related affective experiences of workaholics, the nature of the relationship between workaholism and job demands, and the long-term health effects of workaholism. Additionally, by building on the idea that workaholic women may suffer more negative outcomes than workaholic men due to the conflict between their internal pressures to work and traditional gender role expectations (see Clark, Beiler, \& Zimmerman, 2015), we examine gender as a moderator of the relationship between workaholism and health-related outcomes. We address such issues by using a robust research methodology including multisource and physiological data (i.e., blood pressure) data (Study 1) and a prospective research design with a one-year time lag (Study 2).

\section{The Job-Related Affective Experiences of Workaholics}

In reviewing the most influential definitions of workaholism (e.g. $\mathrm{Ng}$ et al., 2007; Schaufeli, Taris \& Bakker, 2008; Scott, Moore \& Miceli, 1997; Snir \& Harpaz, 2012; Spence \& Robbins, 1992;), Clark et al. (2014) concluded that there is a certain degree of agreement in considering 
workaholism as an addiction that involves feeling driven to work because of internal pressures, having persistent thoughts about work-related issues when not working, and working well beyond what is reasonably expected despite potential negative consequences. Thus, it is widely accepted that cognitive and behavioral aspects are crucial for defining workaholism. On the other hand, there is no agreement among scholars on whether an affective dimension is necessary and, more specifically, on the quality of job-related affective experiences of workaholics.

According to some ( $\mathrm{Ng}$ et al., 2007) an affective dimension is at the core of the workaholism phenomenon, and workaholics, like individuals with other addictive problems (Asher \& Levounis, 2015), experience pleasure and gratification when they carry out the addiction-related behavior that is, when they work. In other words, working is a therapy for workaholics, who from such activity obtain a true affective relief. Additionally, $\mathrm{Ng}$ et al. (2007) contend that when not working, workaholics are dominated by negative affective states such as anxiety, irritability, and guilt, which are believed to be manifestations of a sort of withdrawal symptomatology. A different opinion is that of Spence and Robbins (1992), who agree on the fact that an affective component - which they call work enjoyment - is a defining element of workaholism. However, according to Spence and Robbins (1992) - and others (e.g., Scott et al., 1997) - there are different types of workaholics: Some of them are indeed work enthusiasts, while others - who they believe are the true workaholics - do not enjoy their work. According to Schaufeli et al. (2008), workaholism should be defined as both working compulsively (i.e., the cognitive component) and working excessively (i.e., the behavioral component). Thus, Schaufeli et al. do not consider work-related affective states in their definition and insist that previous conceptualizations emphasizing work-related joy and satisfaction have confounded workaholism with a different form of heavy work investment, namely work engagement (see Taris, Van Beek, \& Schaufeli, 2014). Work engaged employees work hard (vigor), are very involved in their work (dedication), and are happily engrossed in it (absorption), thus being similar to workaholics. However, they do not work hard because they cannot disengage from work, 
but because they really enjoy their work - that is, they lack the strong compulsive tendency to work hard (i.e., drive) that characterizes workaholism (Taris et al., 2014).

The empirical evidence summarized by Clark et al. (2014) is not conclusive in clarifying the job-related affective experiences of workaholics, since workaholism has a small to moderate relationship with work enjoyment and, at the same time and paradoxically, is weakly but negatively related with job satisfaction. Additionally, workaholism is significantly and positively related with negative affectivity. The latter result was interpreted by Clark et al. (2014) by postulating that the negative affect that pervades workaholics when they are not at work outweighs the positive one that they experience at work.

We believe that a more thorough investigation of the job-related affective experiences of workaholics is necessary to resolve some conceptual ambiguities surrounding the phenomenon and for a better understanding of its long-term impact. Job-related affective well-being may be conceptualized by using the two bipolar dimensions of pleasure and mental activation or arousal (Warr, 2007). According to this view, pleasurable affective experiences may be characterized by either high or low arousal (e.g., enthusiasm and satisfaction, respectively). Similarly, unpleasurable affective experiences may either have high (e.g., anger) or low (e.g., discouragement) arousal. Thus, a detailed understanding of the job-related affective experiences of workaholics would require measures covering the spectrum of possible affective states. However, previous research in this area has mainly investigated single facets of job-related affect such as job satisfaction (e.g., Schaufeli, Taris \& van Rhenen, 2008), or it has employed measures of negative and positive affectivity (e.g., Snir \& Zohar, 2008). However, these are context-free measures and have the known characteristic (see Van Katwyk, Fox, Spector, \& Kelloway, 2000) of focusing exclusively on high-arousal affective states. This may explain the inconsistencies that have emerged in the literature.

We argue that the evidence on the relationship between workaholism and negative health and well-being outcomes, including work-related outcomes such as burnout (e.g., Schaufeli et al., 
2009; see below), strongly suggests that workaholics frequently experience negative affect not only when they are not at work, but also at work. Thus, in our Study 1 we tested the hypothesis that workaholism will be positively related with job-related negative affect. However, in order to explore the affective well-being of workaholics more thoroughly, we also examined job-related positive affect. To provide more compelling results for our hypothesis, we not only focus on selfreported affect, but also include an observer-reported measure of affect. Furthermore, since workaholism has been found to be positively related with certain personality dispositions that may influence affective experiences (Clark et al., 2014) - namely Neuroticism and Extraversion - we also controlled for such factors ${ }^{1}$. Thus, our first hypothesis is that:

Hypothesis 1: Workaholism will be positively related with job-related negative affect.

\section{External Pressures and the Genesis of Workaholism}

It is often assumed that the motives for workaholic behavior come mainly from an internal drive rather than organizational pressures and demands and that personality is one of the primary causes of workaholism (e.g. Scott et al., 1997; Snir \& Harpaz, 2012). Accordingly, dispositional characteristics such as perfectionism, low self-esteem, fear of failure, and obsessive compulsive personality traits are seen as possible antecedents of the phenomenon (see Scott et al., 1997). According to Robinson and Kelley (1998), workaholism is a learned addictive response to a dysfunctional family of origin system, similar to type A behavior pattern. That is, it is an enduring disposition which characterizes individuals who are hard-driven, competitive, hostile, and hurried (Friedman \& Rosenman, 1974). In line with this, Robinson and Kelley (1998) found a higher prevalence of psychological problems among offspring of workaholics and, more recently, Kravina, Falco, De Carlo, Andreassen and Pallesen (2013) have shown that the participant's workaholic tendencies were significantly explained by their fathers' workaholic tendencies.

Despite the common assumption that workaholism is primarily a function of personal factors, surprisingly little research has examined the influence of the organizational context in the 
genesis of workaholism. However, $\mathrm{Ng}$ et al. (2007) have proposed an explanation which has its roots in reinforcement theory and that sees workaholic behavior mainly as the result of a system of reinforcements. In other words, if working hard is seen positively within an organization and becomes an important factor in obtaining salary, promotion prospects, and intangible rewards such as good reputation, esteem, and verbal praise, employees have good reason to work harder. Such a mechanism would explain the behavioral dimension of workaholism, but not its mental component (i.e., feeling driven to work).

An alternative explanation is that chronic exposure to certain working conditions such as high job demands and intensive work may have an impact, in the long term, on workaholism. It can be hypothesised, for example, that workaholism is a dysfunctional coping strategy developed in response to chronically high job demands. In other words, an individual constantly facing high job demands may cope by putting more energy and effort into work-related activities and spending progressively more time on them. As a result, work increases in salience and centrality for the individual. There is some evidence that overcommitment - an irrational overinvestment in work activities (Siegrist, 1996) which shares a number of features with workaholism - may be strengthened in a similar way (Avanzi, Zaniboni, Fraccaroli, \& Balducci, 2013). Additionally, there is also evidence that time pressure - a prominent stressor in modern workplaces (Widmer, Semmer, Kalin, Jacobshagen, \& Meier, 2012) - tends to foster work-related rumination (Garst, Frese, \& Molenaar, 2000), which is defined as repetitively thinking about work-related issues. Similarly, unfinished tasks, which may be a frequent experience as a consequence of high job demands, also have an impact on work-related rumination (Syrek \& Antoni, 2014). Such rumination has striking similarities with the cognitive component of workaholism. Consequently, it may well be that certain working conditions indeed contribute to the genesis of workaholism.

If workaholism has a strong dispositional component, then it should impact subsequent job demands, because workaholics' need to overinvest in their job would lead them to actively create a 
higher workload to satisfy that need (Schaufeli, Taris, \& Bakker, 2008; Snir \& Harpaz, 2012). If, however, situational factors play a role in the genesis of workaholism, then job demands should positively impact on the subsequent level of workaholism. Regarding this issue, Clark et al. (2014) concluded that the current state of the evidence does not permit one to draw any clear conclusion on the causal direction of the relationship between organizational pressures such as high job demands and workaholism, and thus there is a need for further research. Because the two causal relationships are both theoretically sustainable and not mutually incompatible, in Study 2 (a prospective study) we sought support for a reciprocal relationship between workaholism and job demands. We thus tested the following additional hypothesis:

Hypothesis 2: Workaholism and job demands will have positive reciprocal effects, such that workaholism will lead to an increase in job demands over time, and job demands will lead to an increase in workaholic tendencies over time.

\section{Workaholism and Health}

Increasing evidence documents that workaholic tendencies are associated with a number of negative stress-related outcomes (Clark et al., 2014). This is theoretically plausible, since workaholics devote most of their time and energy to work-related activities, even during off-job time, thus ending in a sort of vicious cycle of hard work and too little recovery. Both Recovery Theory (see Geurts \& Sonnentag, 2006) and Conservation of Resources Theory (Hobfoll, 1989, 1998) suggest that taking time to recover from work is essential to protect one's health. Recovery is seen as the process of restoring resources - which include cognitive, physical, and emotional energies (Shirom, 2003) - when the person is no longer exposed to the demands of work. What may happen with workaholics is that, by systematically working for long hours (even when not at work), they not only consume time for non-work activities; they also keep activated the same psycho-physiological systems that were already loaded at work. These systems are thus prevented from unwinding and returning to their base level of functioning (Geurts \& Sonnentag, 2006). Then, 
when at work the next day, the workaholic must invest more resources to maintain the same level of performance, augmenting and prolonging the level of sympathetic activation and thus opening the way to the stress process, which may be seen as a series of cycles of energetic resource loss (see Shirom, 2003).

A number of studies have documented a relationship between workaholism and physical, behavioral, and psychological stress-related outcomes such as psychosomatic symptoms (Kubota et al., 2010; Shimazu, Schaufeli, \& Taris, 2010), aggressive behavior (Balducci, Cecchin, Fraccaroli, \& Schaufeli, 2012) and burnout (e.g. Andreassen, Ursin, \& Eriksen, 2007; Avanzi, Van Dick, Fraccaroli, \& Sarchielli, 2012; Burke, Richardsen, \& Mortinussen, 2004). However, with few exceptions (e.g. Avanzi et al.. 2012; Falco et al., 2013), research in this area has rarely implemented prospective studies to examine the issue, and even more rarely has it integrated objective data into the analyses. Both of these issues should be addressed to reach clarity about the health effects of workaholism.

Thus in Study 1 we examined the relationship between workaholism and blood pressure, that is, an objective health measure. Blood pressure is considered a physiological outcome of the stress process (Ganster \& Rosen, 2013), resulting from the high sympathetic activation which accompanies the experience of stress. By fuelling the stress process, it is possible and indeed likely that workaholism also leads to physiological outcomes such as high blood pressure. Additionally, in Study 2 we conducted a test of the long-term health effects of workaholism by examining whether workaholism would impact on the level of mental distress reported after one year. A positive result of such test would strengthen the evidence of previous research, mostly based on cross-sectional studies.

Thus, we also expected to find that:

Hypothesis 3: Workaholism will be positively related with blood pressure. Hypotheses 4: Workaholism will have a positive impact on mental distress over time. 


\section{Gender as a Moderator}

Although research has repeatedly found that men report higher workaholic tendencies than women (e.g. Schaufeli et al., 2008), overall such differences have been found to be relatively small and non-significant (see Clark et al., 2014). On the basis of such evidence, Clark et al. (2014) concluded that contrary to what one might expect on the basis of, for example, prevailing cultural schemas that men are more invested in work and women more invested in family, men are not more likely to be workaholics than women. However, as recently suggested by Clark et al. (2015), workaholic women may experience unique tension as they try to find a balance between their inner drive to be heavily invested in work, while also adhering to the traditional cultural schema that women should care for the home and family (see also Blair-Loy, 2003; Powell \& Greenhaus, 2010). In contrast, this kind of role conflict is not experienced by workaholic men, whose work addiction aligns with the prevailing schema that men should give priority to their professional career in order to secure a good income.

The additional pressure experienced by workaholic women may directly determine more negative health and well-being outcomes for them. It may also lead to more negative outcomes by amplifying women's increased self-focused rumination on negative emotional states (see Johnson \& Whisman, 2013) or by fueling higher levels of work-family conflict (Clark et al., 2015.) It is thus possible that, although women and men are equally likely to be workaholics, women report more negative consequences from their work-related addiction. We are not aware of studies that have investigated this possibility and more generally that have looked at the differential impact of workaholism on the two genders. Thus in Study 1 and Study 2, respectively, we also tested the following hypotheses:

Hypothesis 5: The positive relationship between workaholism and job-related negative affect will be moderated by gender, so that the relationship will be stronger among women than among men. 
Hypothesis 6: The positive effect of workaholism on mental distress will be moderated by gender, so that the effect will be stronger among women than among men.

Based on the above considerations, we additionally explored the possibility of a workaholism by gender interaction on blood pressure. However, we did not explicitly hypothesize such an interaction because, on the one hand, women workaholics may be more vulnerable to stress-related outcomes including high blood pressure, while on the other hand, male gender is a well established risk factor for higher blood pressure (see Vasan, 2009).

\section{STUDY 1}

\section{Method}

Participants and procedure. Study 1 focused on a heterogeneous sample of workers. Participants were contacted among acquaintances of the researchers and by means of snowball sampling. A total of 311 individuals took part in the study. The data were collected by means of two questionnaires, one of which was administered to the study participant, and the other to his/her partner $(65.3 \%)$, another cohabiting family member $(11.3 \%)$ or - in the remaining cases $-\mathrm{a}$ colleague/collaborator with whom the participant interacted on a daily basis. Data collection took place in most cases at the participant's home in the afternoon or evening during non-working time. Participants were males in $58.5 \%$ of the cases and had a mean age of 46.4 years $(S D=10.0)$. They had completed compulsory education in $15.2 \%$ of cases, $48.1 \%$ had an upper-secondary diploma, and $36.8 \%$ a college degree. Most of the participants worked in the private sector $(71.1 \%)$. They were self-employed workers or entrepreneurs $(43.7 \%)$, managers $(15.1 \%)$ and employees in the remaining cases.

Self-report questionnaire. All the multi-item measures used in the survey had been previously adapted into Italian by means of the back-translation method.

Workaholism was measured by using the 10-item version of the Dutch Work Addiction Scale (DUWAS; Schaufeli, Shimazu, \& Taris, 2009). The DUWAS investigates the two 
components of workaholism (i.e. working compulsively, WC, and working excessively, WE) by means of ten items, examples of which are the following: "I feel that there's something inside me that drives me to work hard" (WC) and "I stay busy and keep many irons in the fire" (WE). Responses were given on a 4-point scale varying from 1 ("Never or almost never") to 4 (“Almost always or always"). Since both the components investigated contribute to the workaholic syndrome and they were strongly intercorrelated in the present study $(r=.54, p<.001)$, we followed the example of others (e.g. Robinson \& Kelley, 1998; Schaufeli, Bakker, van der Heijden, \& Prins, 2009; van Beek et al., 2011) and derived an overall workaholism score. The main reason that we used the DUWAS is because, contrary to its main alternatives, the Work Addiction Risk Test (Robinson, 1989) and the Workaholism Battery (Spence \& Robbins, 1992), the DUWAS has strong psychometric properties (see Snir \& Harpaz, 2012). Additionally, it focuses exclusively on the two dimensions (i.e., being driven to work and working hard) that most researchers in the area consider crucial in defining workaholism (see Clark et al., 2014), and it has been validated in the national context of the present research (Balducci, Avanzi, Consiglio, Fraccaroli, \& Schaufeli, 2015). Job-related negative affect and job-related positive affect were assessed by four items each derived from a shortened version (see Schaufeli \& van Rhenen, 2006) of the Job-related Affective Well-being Scale (JAWS; Van Katwyk et al., 2000) that has already been used in previous research (Balducci et al., 2012). The JAWS investigates the frequency of positive and negative (including both high and low arousal) job-related affective states associated with an individual's work across the previous 30 days, with responses given on a 5-point scale ranging from 1 ("Never") to 5 ("Very often/almost daily"). The negative affective states assessed in our study were anger, disgust, pessimism, and discouragement, while the positive states were satisfaction, calmness, enthusiasm, and energy.

Neuroticism and Extraversion were measured by using a Big Five model questionnaire, the Ten Item Personality Inventory (TIPI; Gosling, Rentfrow, \& Swann, 2003). This instrument 
consists of 10 items introduced by the common stem "I see myself as...", with each Big Five dimension tapped by two items which capture its different poles. Responses to items are given on a seven-point scale ranging from 1 (“Disagree strongly") to 7 (“Agree strongly”). Goslin et al. (2003) have shown that, although this measure is somewhat inferior to standard multi-item personality inventories, it reaches adequate levels of convergence with widely-used Big-Five measures, testretest reliability, patterns of predicted external correlates, and convergence between self and observer ratings. However, since the internal consistency of the five personality scales was found to be unacceptably low in the present sample $(\alpha<.50$ in all cases), following McRae and Weiss suggestion (2009) we decided to combine the self-reported personality items with the parallel observer-reported ones (see below). With this strategy we obtained a sufficient internal consistency for the two scales measuring the dimensions of interest, that is Neuroticism (example item: “Anxious, easily upset") and Extraversion ("Extraverted, enthusiastic").

Observer-report questionnaire. Job-related negative affect and job-related positive affect were measured by using a shortened version of the Job-related Affective Well-being Scale (JAWS), which has already been described above. The observer was asked to indicate how often in the last 30 days he/she had observed in the target person manifestations of each of the eight investigated affective states in relation to the target person's job. The observer was also asked to evaluate participant's personality, including Neuroticism and Extraversion, by using the Ten Item Personality Inventory (TIPI), which has also been described above.

Blood pressure. For a subsample of participants $(N=217)$ blood pressure was also measured. This was done by means of a portable upper arm blood pressure monitor device (a digital sphygmomanometer). Blood pressure was measured after the participant had rested quietly while sitting for five minutes, after he/she had filled in his/her questionnaire. A member of the research team was present during data collection and usually took the participant's blood pressure measure. In the analyses, we focused exclusively on systolic blood pressure because it is increasingly 
believed that this is the crucial indicator of high blood pressure, especially in middle aged and older individuals $^{2}$. Additionally, we eliminated participants who were taking medications to control blood pressure, which yielded a final sample of $N=189$ individuals.

Data analyses. After examining correlations between the study variables, to test the main hypotheses we conducted a series of hierarchical multiple regression analyses following Cohen, Cohen, West, and Aiken's (2003) recommendations. Missing observations were dealt with separately in the analyses on job-related affect and blood pressure. In both cases the multiple imputation procedure available in SPSS 22 was used, with 50 imputations of the original dataset being performed (see Graham, 2009).

\section{Results and Discussion}

Table 1 shows that workaholism was significantly and positively related to job-related negative affect, either self- $(r=.31, p<.001)$ or observer $(r=.17, p<.01)$ reported. By contrast, workaholism was not related with job-related positive affect. Workaholism showed also a significant and positive correlation with neuroticism $(r=.18, p<.01)$.

Insert Table 1 about here

The results of the regression analyses (Tables 1-2, step 3 of the analyses) are consistent in revealing that workaholism is positively and significantly associated with job-related negative affect, thus supporting Hypothesis 1. Furthermore, the workaholism by gender interaction was also significant in the analysis focusing on self-reported job-related negative affect $(B=.38, S E=.19, p$ $<.05)$, while it was just above the significance level $(B=.36, S E=.19, p=.059)$ in the analysis focusing on observer-reported job-related negative affect. Simple slope analysis (see Figure 1) revealed that the relationship between workaholism and self-reported job-related negative affect was substantially stronger among females $(B=0.37, \mathrm{SE}=0.07, p<.001)$ than among males $(B=$ 
$.18, S E=.07, p<.01)$. The results presented a similar pattern when focusing on observer-reported job-related negative affect. Overall we found substantial support for Hypothesis 2.

Insert Table 2, Table 3 and Figure 1 about here

Table 3 shows that workaholism was significantly and positively related to systolic blood pressure, $B=1.74, S E=0.87, p<.05$, which provided evidence in line with Hypothesis 3 . However, the interaction between workaholism and gender was non-significant, meaning that workaholism did not have a differential impact among men and women as far as blood pressure is concerned.

Insert Table 4 about here

\section{STUDY 2}

\section{Method}

Participants and procedure. Study 2 was conducted in a National Healthcare Service Agency in the North of Italy. Data collection was carried out as part of a two-wave psychosocial risk assessment project with a time lag of one year. The data were collected by means of an anonymous self-reported questionnaire, which was administered during working hours. Sixteen different departments of the Agency were selected by the Health and Safety office according to their performance on a number of indicators considered by the Italian Health and Safety Law as possible consequences of job stress (e.g. sickness absence, turnover, disciplinary procedures). The researchers did not directly take part in the selection process. A total of 574 employees filled in the time 1 (T1) questionnaire, with an average response rate of $75.4 \%$ in the various departments. The time 2 (T2) questionnaire was completed by 508 employees, with an average response rate of 65\%. The T1 and T2 questionnaires were matched using anonymous codes which respondents created 
from personal information. The final sample for the prospective analysis reported here consisted of the 235 employees ( $40.9 \%$ of those filling in the T1 questionnaire) for which matching between the two questionnaires was possible. Since the data collected were very sensitive, socio-demographic variables included in the questionnaires were formulated so as to minimize the possibility of participant identification (e.g. the age variable was assessed using broad age classes). The sample was $86.3 \%$ female, while their modal age category was $40-49$ years $(37.8 \%)$, followed by $30-39$ years (37.3\%). Most of the participants were nurses (72.7\%). Also represented were doctors, administrative staff, and other types of workers (e.g. cleaning staff). Job tenure was 5 years or more in the great majority of cases (83.0\%). Almost all participants had a permanent job contract (97\%).

Questionnaire. Workaholism was measured by using the 10-item version of the Dutch Work Addiction Scale (DUWAS; Schaufeli, Shimazu, \& Taris, 2009), described in Study 1. Job demands were measured by using five items (e.g. "I have to work very fast") included in the job demands scale of the Job Content Questionnaire (JCQ; Karasek et al., 1998). Responses to items were given on a 4-point scale ranging from 1 (" strongly disagree") to 4 ("'strongly agree"). Mental distress was assessed by using the 12-item version of the General Health Questionnaire (GHQ-12; Goldberg, 1972). The GHQ-12 investigates the respondent's experience of a number of symptoms worded in positive terms (e.g. "You have been capable of making decisions"') or negative ones ("You have felt constantly under strain"). Responses ranged from 0 ("No" or " More than usual", according to specific items) to 3 ("Much more than usual" or "Much less than usual'"). The GHQ-12 has been well validated (e.g. Piccinelli, Bisoffi, Bon, Cunico, \& Tansella, 1993), with factor analytic studies suggesting that it investigates three strongly-correlated factors: social dysfunction, general dysphoria and loss of self-confidence. To assign a total score to each participant, we used the so-called CGHQ scoring method (see Whaley, Morrison, Payne, Fritschi, \& Wall, 2005) in which each symptom is scored dichotomously in terms of its presence. Thus, the 
GHQ-12 total score varied from 0 to 12 , with higher scores indicating higher levels of psychological distress.

Data analysis. After conducting a preliminary attrition analysis and examining correlations among the study variables, we fit a series of full panel path analytic models using LISREL 8.71 (estimation method: full information maximum likelihood), including gender and the main study variables (i.e. mental distress, workaholism and job demands) as measured at both T1 and T2. To

assess the fit of the tested models and the study hypotheses we relied on the chi square $\left(\chi^{2}\right)$ statistic. Additionally, we also examined the Root Mean Square Error of Approximation (RMSEA), with models showing values of up to .08 at this statistic being usually considered acceptable (see, e.g., Tabachnick \& Fidell, 2007). Nested models were evaluated by using the $\chi^{2}$ difference test ${ }^{3}$.

\section{Results and Discussion}

Before testing the main study hypotheses, we conducted an attrition analysis in order to explore whether the variables on which the main analyses focused were related to drop-out from the study, thus potentially biasing parameter estimates. We specifically conducted a logistic regression analysis (see Miller \& Hollist, 2007) on the 574 participants to the T1 survey, in which the outcome was participation vs. drop-out from the T2 survey and the risk factors were all the study variables: workaholism, job demands, psychological distress and gender. We found that gender was strongly related to drop-out, with males being significantly more likely to drop out from the study than females (Odds Ratio $=2.97, \mathrm{p}<.001)$. Since the cause of missingness (i.e. gender) was included in the following analyses, parameter estimates could be assumed as accurate (see Graham, 2009, p. $553)$.

Table 4 reports descriptive statistics and intercorrelations among study variables. It shows that workaholism was positively and significantly correlated with both job demands and mental distress, with synchronous correlations being generally higher than lagged correlations. We then fit a series of path analytic models to the data. We describe the results of these analyses in terms of fit 
indices and standardized paths. The baseline model (model 1) against which we tested Hypotheses 2 and 4 (i.e. that workaholism and job demands will have positive reciprocal effects and that workaholism will positively impact on mental distress, respectively) included covariances among workaholism, job demands and psychological distress at both T1 and T2, as well as autocorrelations of the same variables across time. It also included gender as a further exogenous variable covarying with the T1 variables and impacting on T2 mental distress. This baseline model obtained the following fit, $\chi^{2}(8)=24.32, p=.002 ; \mathrm{RMSEA}=.094$. In this model, the path from gender to T2 psychological distress was statistically significant, $\gamma=.11, t=2.07, p<.05$, indicating that female participants reported a higher level of mental distress than did male participants. We then estimated a second model (model 2) in which we included the paths related to hypotheses 2 and 4, stating that workaholism and job demands will have positive reciprocal effects and that workaholism will have a positive effect on psychological distress, respectively. The resulting model fit (i.e. $\chi^{2}(5)=10.01$, $n s ;$ RMSEA $=.066)$ was statistically significantly better than the baseline model, $\Delta \chi^{2}(3)=14.31, p$ $<.05$. In this model, which is represented graphically in Figure 1, the path from T1 workaholism to T2 mental distress was statistically significant, $\gamma=.17, t=2.80, p<.01$, explaining $2.5 \%$ additional variance in the target variable. Furthermore, the path from $\mathrm{T} 1$ job demands to T2 workaholism was also statistically significant, $\gamma=.14, t=2.38, p<.05$, explaining $2.2 \%$ unique variance in $\mathrm{T} 2$ workaholism. However, the path from T1 workaholism to T2 job demands was not statistically significant, $\gamma=.05, t=0.74, n s$. These results lent support to Hypothesis 4 , that $\mathrm{T} 1$ workaholism will positively impact T2 mental distress. However, the results did not support Hypothesis 2, according to which workaholism and job demands would have reciprocal positive effects. Rather, the data only supported the view that workaholism may be strengthened by certain working conditions, namely working constantly under time pressure and having many tasks to accomplish (i.e. job demands). 
Insert Figure 2 about here

To test Hypothesis 6, that the impact of T1 workaholism on T2 mental distress will be strengthened in women, we modified the baseline model described above (model 1) by adding as a further exogenous variable, the gender by T1 workaholism interaction. This variable covaried exclusively with T1 job demands and T1 mental distress (see Cortina, Chen, \& Dunlap, 2001). Additionally we included the path from T1 workaholism to T2 mental distress and the path from T1 job demands to T2 workaholism - that is, the significant paths emerged in model 2 (see above).

This baseline model showed the following fit: $\chi^{2}(11)=10.92, n s ;$ RMSEA $=.040$. The addition of the path from the gender by $\mathrm{T} 1$ Workaholism interaction to T2 mental distress did not improve the fit of the model $\left(\Delta \chi^{2}(1)=0.31, n s\right)$, and the tested path was not statistically significant, $\gamma=.07, t=$ 0.54, ns. Thus Hypothesis 6 was not supported.

\section{GENERAL DISCUSSION}

The aim of the research reported here was to improve the quality of the available evidence on workaholism by using multisource and prospective data. We specifically focused on three open issues identified by a recent meta-analysis on the phenomenon (Clark et al., 2014), namely, the quality of the job-related affective experiences of workaholics, the nature of the relationship between workaholism and job demands, and the long-term health effects of workaholism. Additionally we also examined gender as a moderator of the workaholism-outcomes relationships. Workaholism and Job-Related Affect

The results emerging from the Clark et al (2014) meta-analysis on the relationship between workaholism and affectively laden constructs were ambiguous. One of Clark et al.'s tentative conclusions was that the available evidence is compatible with the view that workaholics have a general tendency to report negative affectivity more frequently. On the other hand, when they are at work they indeed experience a prevalence of positive affective states such as work enjoyment. 
However, the meta-analytic data were not entirely consistent with this idea, since workaholism was positively related with work enjoyment but negatively related with job satisfaction.

We found that workaholism positively predicted the frequency of job-related negative affective states experienced by the participants. This result indicates that workaholic tendencies go hand in hand with affective experiences such as anger, disgust, and pessimism, related to one's work. Furthermore, we did not find evidence that workaholism is significantly related with jobrelated positive affect (enthusiasm, satisfaction, energy, etc. $)^{4}$. These results do not lend support to the idea that workaholics are generally happy workers (e.g. Baruch, 2011). Overall our results strongly undermine the validity of those definitions of workaholism for which positive job-related affective experiences are core elements of the phenomenon ( $\mathrm{Ng}$ et al., 2007).

We believe that our findings constitute a step ahead towards understanding of the affective nature of workaholism because, in contrast with previous research (e.g. Snir \& Zohar, 2008), we used more comprehensive measures of job-related affect. Additionally we relied not only on selfreported data, but we also used observer reported data, and we controlled for the potential confounding effect of neuroticism (i.e. negative affectivity) which by definition is a strong determinant of the affective experiences of individuals and which has been found to be related with workaholism (see Clark et al., 2014).

On the basis of the above results we may contribute to the debate on the importance of an affective component for the definition and measurement of workaholism (see Ng. et al., 2007; Taris et al., 2014). Although it seems clear that reporting workaholic tendencies is related to experiencing negative job-related feelings, the size of the relationship that emerged (i.e. $r=.31$ ) was not so strong as to justify the inclusion of an affective component in workaholism. Thus the solution to exclusively focus on the mental and behavioral dimensions of the phenomenon (see Schaufeli et al., 2008), which in our study were strongly intercorrelated (i.e. $r=.55$ ), seems the most empirically justifiable. Such a solution has the advantage of including the components considered central to the 
syndrome by the most common definitions of workaholism (see Clark et al., 2014), and it does not run the risk of confounding workaholism with one of its possible consequences (i.e. job-related affective experiences).

\section{Workaholism and Job Demands}

Clark et al.'s (2014) meta-analysis found a strong relationship between workaholism and job demands (i.e. workload). However, all of the reviewed studies were cross-sectional so they could only speculate about the true nature of such a relationship. By taking advantage of a longitudinal dataset we advanced the understanding of the link between workaholism and job demands. Contrary to what we expected (Hypothesis 4), we did not find evidence for reciprocal lagged effects between workaholism and job demands. What we found is that higher levels of job demands, which were operationalized mainly in terms of mental workload, led to increased workaholic tendencies over time, while workaholism does not impact job demands. Different conceptualizations of workaholism (Scott et al., 1997; Snir \& Harpaz, 2012) have emphasized its nature as a stable individual characteristic deriving from operational models internalized in adolescence or early adulthood (Robinson \& Kelley, 1998). Our results do not support such idea. Rather, our findings suggest that exposure to a demanding work environment may be implicated (at least in part) in the development or reinforcement of work addiction.

We have proposed different explanations for why situational factors such as high job demands may lead to workaholism. Syrek and Antoni (2014) explained the role of unfinished tasks - which may be a consequence of high job demands - on work-related rumination by means of the widely known Zeigarnik effect, which refers to the automatic and intrusive thoughts about a goal that was once pursued and left incomplete. Unfinished tasks may cause work-related rumination through the experience of lack of closure and sense of completion. Rumination closely resembles the cognitive component of workaholism (i.e. having difficulty in detaching oneself mentally from work-related issues), which may thus develop as a consequence of unfinished tasks. Such 
rumination, then, may directly fuel working excessively - i.e. the behavioral component of workaholism - which may be a coping strategy implemented to deal with work-related rumination. Thus the individual may work for long hours and bring the work home as a way to complete unfinished tasks, which would permit to dissolve the intrusive cognitions generated by high job demands. However, if exposure to high demands is chronic, as it is the case for many jobs in the modern economy (see Naswall et al., 2008), the adopted coping strategy (i.e. working excessively) does not work because new unfinished tasks will follow, which will fuel new work-related rumination.

We note that the proposed explanation is not incompatible with the view that there is a dispositional (and stable) component of workaholism. Modern cognitive theory (Harvey, Watkins, Mansell, \& Shafran, 2004) suggests that much psychological dysfunction is the product of the joint effect of predispositions and precipitating factors such as environmental conditions and events. This may also be the case for workaholism.

\section{Workaholism and Health}

In their meta-analysis Clark et al. (2014) found strong and consistent evidence that workaholism is linked with negative individual outcomes such as poor mental and physical health, burnout, and job stress. However, they emphasized that the majority of studies included in their analysis was based on cross-sectional and self-reported data.

Our research adds new and robust evidence to the existing literature based on prospective and objective data. In Study 1 we found that workaholism is positively related to systolic blood pressure, a result that sheds light on the potential far-reaching health effects of workaholism. Such result is not totally surprising given the constituent components of the phenomenon, among them working excessively. Research has indeed found that working long hours is a risk factor for high blood pressure (e.g. Yang, Schnall, Jaurequi, Su, \& Baker, 2006). Furthermore, working excessively is also associated with fatigue and sleep problems, which may increase the sympathetic 
nervous system's activity and then the heart rate and blood pressure (Landsbergis, 2004). The compulsive aspect of workaholism may also play a role here: for example, by fuelling feelings of anxiety which directly affect heart rate and blood pressure.

In Study 2, in line with what we hypothesized, we also found that the baseline levels of workaholism were positively related with the follow-up levels of mental distress. This result was not confounded by the level of workload reported by the participant, which is a well-established risk factor for mental distress (see Häusser, Mojzisch, Niesel, \& Schulz-Hardt, 2010). One of the key mechanisms to explain the impact of workaholism on mental health may be the lack of recovery (see Schaufeli et al, 2009) and the associated loss of energetic resources (Shirom, 2003). Normally, after work people feel fatigued, but this is inconsequential if the individual stop the activity which leads to such a feeling. In such cases the recovery process normally starts, and fatigue disappears. If, however, the fatigue-inducing activity is not discontinued, as happens in workaholics (see Bakker et al., 2013), a cumulative process involving prolonged fatigue with potential adverse health effects may follow (Geurts \& Sonnentag, 2006). This is because the individual continues to invest in work-related activities a limited amount of resources, with the consequence that the resource reservoir can empty. Resource loss and lack of resource restoration are crucial precursors of stress and burnout (Hobfoll, 1989, 1998) and thus of a deteriorated mental health. In future research it would be interesting to directly investigate the role of recovery and personal resource loss as far as the long-term effect of workaholism is concerned.

\section{The Moderating Role of Gender}

As hypothesised, we found that workaholic tendencies were particularly insidious for female workers in terms of emotional experiences. Clark et al. (2014) have noted that most research in this area has simply investigated gender differences in workaholism or has used gender as a control, rather than examining it as a substantive variable in the analyses. More recently Clark and colleagues (2015), focusing on the work-family experience of workaholics, have proposed that 
workaholic women may face extra pressures due to the conflict between their inner drive to work and traditional gender role expectations. They thus speculated that workaholic women may suffer even greater negative consequences compared to their male counterparts. In the present research we have found some evidence in line with this idea: workaholic tendencies seem to lead to greater negative emotional reactions in women than in men. This could be the result of women workaholics indeed experiencing more pressure than men to devote time to family work and responsibilities, which would be in line with sex role theory and prevailing cultural schemas (e.g. Blair-Loy, 2003). It could also be that women workaholics experience higher levels of work/family conflict (see Burke, 2008), which would act as an intervening variable in the workaholism-negative job-related affect relationship.

Contrary to what we expected, however, in Study 2 we did not find that the negative impact of workaholism on mental distress was strengthened in women, when compared to men, which is a bit surprising given the result that workaholic tendencies seem to lead to more job-related negative affective experiences in women. Negative affective states are generally considered a short-term stress reaction (e.g. Lazarus, 2006). On the other hand, mental distress including clinically relevant symptoms of anxiety and depression may be viewed as a more profound long-term effect of stress. Thus, it is possible that while a focus on short-term stress reactions reveals a disadvantage for women with higher workaholic tendencies, given also their higher emotional vulnerability (Johnson \& Whisman, 2013), in the long term the deleterious effects of workaholism affect men and women equally. This explanation would also fit the result of a lack of a workaholism by gender interaction on blood pressure, given that increased blood pressure may be seen as a long-term effect of the stress process (Ganster \& Rosen, 2013).

Alternatively, there may be methodological reasons to explain why the gender by workaholism interaction did not emerge on long-term health outcomes. For example, the samples available were smaller in size ( $N=189$ for Study 1 , and $N=235$ for Study 2). Additionally Study 2 
included only a small proportion of men ( $13.7 \%$ of the cases). Thus, overall we were not in the best position in terms of statistical power to detect an interaction effect; this suggests the idea of conducting more research on the differential health impact of workaholism according to gender.

\section{Methodological Issues, Limitations and Future Directions}

Because this study included two field samples, it is not without potential limitations. First, the Study 1 sample consisted of participants with very different employment roles (i.e. selfemployed workers, managers, and employees). Although research on differences in health and wellbeing among these different employment roles is not well-developed (Warr, 2007), it would have been better to directly assess (and control for) specific health-related working conditions which contribute to the occupational differences among these roles. Additionally, even though the criterion variables in Study 1 were not exclusively self-reported and included also objective data, the study was cross-sectional, meaning that conclusions on the causal nature of the relationships found (i.e. between workaholism and job-related affect and between workaholism and blood pressure) are precluded. Longitudinal investigations (including diary studies) are necessary for this purpose. Another limitation of Study 1 is that blood pressure was measured only once, while the best way to measure blood pressure is to take repeated measurements in the course of the day and then consider the average (see Landsbergis et al., 2003). Furthermore, in the analyses we controlled only for two of the five Big Five factors of personality, with the internal consistency (i.e., alpha) of the adopted measures being at a suboptimal level. However, we note that we controlled for the only two factors (i.e., Neuroticism and Extraversion) which have proved to be significantly associated with workaholism (Clark et al., 2014) and that past research has rarely included personality factors particularly Neuroticism - when assessing the potential effects of workaholism. We also note that alpha as a measure of reliability is strongly influenced by the number of items composing the measure and that for measures of only a few items as in our case, alpha may actually be misleading as reliability estimate (see, e.g., Sijtsma, 2009). Finally, we did not assess the actual number of 
hours worked by participants, which may be needed to document whether workaholic tendencies have an effect on health over and above this variable. For a subsample of participants of Study 1 (N =99) we had available the actual number of hours worked per week, and this variable correlated only moderately with workaholism $(r=.27)$. Similarly, research has found only a moderate relationship between hours worked and workaholism, and there is agreement that measuring workaholism by relying on actual numbers of hours worked may be misleading since it does not take into account the reasons why the individual works long hours (Clark et al., 2014).

As for Study 2, the sample consisted solely of employees. Employees have a working day which lasts a fixed number of hours, so that they may be less likely to exhibit some aspects of the workaholic syndrome (especially as far as working excessively is concerned). Furthermore, nurses which made up the majority of the Study 2 sample - have been found to report lower levels of workaholism in comparison to other professions (Taris, van Beek, \& Schaufeli, 2012). In line with this finding, the mean level of workaholism in Study 2 was significantly lower than that found in Study 1 , in which the sample was mostly made by self-employed individuals, managers and entrepreneurs. Moreover, Study 2 was conducted in the health sector, which is notoriously a highrisk sector as far as the prevalence of work-related stress is concerned. Such sample characteristics may pose problems regarding the generalizability of the observed relationships.

A further potential limitation of Study 2 is that we did not assess personality factors. However, the full panel design adopted should have ruled out the possible confounding effect of constant third variables such as personality dispositions (see Zapf, Dormann, \& Frese, 1996).

It could be interesting in future studies to search for further possible moderators of the workaholism-health relationship, such as job resources. High job control, for instance, may compensate for the need to exert control which is typical in obsessive-compulsive problems (Morrison \& Westbrook, 2004), of which workaholism is considered an example (Robinson, 1989), thus reducing the negative effects of workaholism. However, it is equally possible that with more 
job control (e.g. over one's working time) workaholics over-indulge in work-related activities, thus reporting more negative effects. Additional moderators of the workaholism-health relationships could also be taken into consideration such as organizational overwork climate (Mazzetti, Schaufeli, \& Guglielmi, 2014) and societal and cultural aspects (Hu, Schaufeli, Taris, van Hessen, Hakanen, Salanova, \& Shimazu, 2014). Future research should also try to implement longitudinal designs: for example, in order to examine the stability and change of workaholic tendencies and their predictors and consequences. Such designs, which require at least three-wave data (see Ployhart \& Vandenberg, 2010), are sorely needed in this area of research (Clark et al., 2014). Diary studies examining short-term fluctuations in job-related affect as a function of workaholism would also be useful, to further understand the emotions felt by workaholics in situ (see Clark et al., 2014).

\section{Practical Implications}

Given the evidence of our two studies on the negative health effects of workaholism, which adds to the findings on its social impact (e.g. Shimazu, Demerouti, Bakker, Shimada, \& Kawakami, 2011), it seems important to consider possible preventive measures. From a primary prevention perspective, organizations could take steps to raise awareness among employees that workaholic tendencies have a significant detrimental impact on health. Information and training (e.g. workshops) at all organizational levels could serve this purpose. Managers should be the primary target of such interventions, since they frequently report workaholic tendencies (Brett \& Stroh, 2003) and, by acting as models of behavior for employees, they contribute to creating a 'workaholism culture' where the workaholic tendencies of individuals may be considered functional. Furthermore, from a job design perspective, monitoring exposure to job demands, and if necessary intervening to adapt them to the capacity of employees to manage them, would also be of help. If workaholism is indeed a function of a very high workload, as our Study 2 suggests, then managers and supervisors should ensure that the demands placed on employees remain manageable during the normal working time. As an aid in achieving this, they could also assist employees to 
find ways to perform work more efficiently and provide positive feedback for a productive time management (see Holland, 2008).

Work-family programs, for example programs aiming at developing family-supportive leadership behavior (Hammer, Kossek, Yragui, Bodner, \& Hanson, 2009) may also be of help, since by promoting family involvement they alleviate excessive work investment. It is noteworthy that family involvement has also been found to promote the accumulation of resources from the family which can be transferred to the workplace, with positive effects on employees' well-being (Russo, Buonocore, Carmeli, \& Guo, 2015) and performance-related outcomes (Paustian-Underdahl, Halbesleben, Carlson, \& Kacmar, 2013).

From a secondary prevention perspective, a recent study by Bakker et al. (2013) has found that recreational activities like sports are particularly beneficial in terms of well-being for workaholics. Thus, organizations could encourage employees to participate in such activities during non-work time, for example by offering incentives for such participation and by directly organizing sports events during the year. These activities may alleviate stress-related symptoms, particularly for workaholics.

Finally, from a tertiary prevention perspective, there may be an important place for individual counseling and therapy in the alleviation of workaholism. Currently, there are no evidence-based interventions for addressing workaholism (Asher \& Levounis, 2015). However, since one of the crucial components of the phenomenon is its compulsive nature, cognitive behavioral therapy approaches may be a good choice, since they address the underlying beliefs and attitudes that may cause an individual to work excessively. Over the course of the treatment, the workaholic should be led to set boundaries between work and home and to schedule time for extrawork entertainments such as self-care, play, and social activities. The person should also be led to develop greater self-awareness, increasing empathy for others and being more effective at work" (see Asher \& Levounis, 2015). Finally, self-help groups such as Workaholics Anonymous, in which 
workaholism is considered a true disease and a multistep treatment is offered for recovering from it may also be an option from a tertiary prevention perspective (see Sussman, 2012).

However, since among contemporary organizations the 'long work hours culture' (see Burke \& Cooper, 2008) is a pervasive phenomenon, which may imply that workaholism is not regarded as a psychological dysfunction, public health initiatives such as information campaigns promoted by governmental health agencies may also be needed. These would also be of help in eradicating the widespread belief - still present even among organizational scholars (Baruch, 2011) - that workaholism may be a constructive and beneficial phenomenon. 


\section{REFERENCES}

Andreassen, C. S., Ursin, H., \& Eriksen, H. R. 2007. The relationship between strong motivation to work, "workaholism", and health. Psychology and Health, 22: 615-629.

Asher, M. S., \& Levounis, P. 2015. The behavioral addictions. Arlington, VA : American Psychiatric Association Publishing.

Avanzi, L., van Dick, R., Fraccaroli, F., \& Sarchielli, G. 2012. The downside of organizational identification: Relations between identification, workaholism and well-being. Work \& Stress, 26: 289-307.

Avanzi, L., Zaniboni, S., Fraccaroli, F., \& Balducci, C. in press. The relation between overcommitment and burnout: Does it depend on employee job satisfaction? Anxiety, Stress \& Coping. doi: 10.1080/10615806.2013.866230

Bakker, A. B., Demerouti, E., Oerlemans, W., \& Sonnentag, S. 2013. Workaholism and daily recovery: A day reconstruction study of leisure activities. Journal of Organizational Behavior, 34: 87-107.

Balducci, C., Avanzi L., Consiglio, C., Fraccaroli, F., \& Schaufeli, W. 2015. A cross-national study on the psychometric quality of the Italian version of the Dutch Work Addiction Scale (DUWAS). European Journal of Psychological Assessment. doi: 10.1027/1015$5759 / \mathrm{a} 000300$

Balducci, C., Cecchin, M., Fraccaroli, F., \& Schaufeli, W. B. 2012. Exploring the relationship between workaholism and workplace aggressive behaviour: The role of job-related emotion. Personality and Individual Differences, 53: 629-634.

Baruch, Y. 2011. The positive well-being aspects of workaholism in cross cultural perspective. Career Development International, 16: 572-591.

Blair-Loy, M. 2003. Competing devotions: Career and family among women executives. Cambridge, MA: Harvard University Press. 
Brett, J. M., \& Stroh, L. K. 2003. Working 61 plus hours a week: Why do managers do it? Journal of Applied Psychology, 88: 67-78.

Burke, R. J. 2008. Preface. In R. J. Burke \& C. L. Cooper (Eds.), The long work hours culture: Causes, consequences, and choices: ix-xxvii. Bingley, UK: Emerald Publishing Group.

Burke, R. J., \& Cooper, C. L. (Eds.) 2008. The long work hours culture: Causes, consequences, and choices. Bingley, UK: Emerald Publishing Group.

Burke, R. J., Richardsen, A. M., \& Martinussen, M. 2004. Workaholism among Norwegian senior managers: New research directions. International Journal of Management, 21: 415-426.

Clark, M., Beiler, A. A., \& Zimmerman, L. M. 2015. Examining the work-family experience of female workaholics. In M. J. Mills (Ed.), Gender and the work-family experience: 313-327. New York: Springer.

Clark, M. A., Michel, J. S., Zhdanova, L., Pui, S. Y., \& Baltes, B. B. 2014. All work and no play? A meta-analytic examination of the correlates and outcomes of workaholism. Journal of Management. doi: 10.1177/0149206314522301

Cohen, J., Cohen, P., West, S. G., \& Aiken, L. S. 2003. Applied multiple regression/correlation analysis for the behavioral sciences. Mahwah, NJ: Lawrence Erlbaum Associates.

Cortina, J. M., Chen, G., \& Dunlap, W. P. 2001. Testing interactions effects in LISREL: Examination and illustration of available procedures. Organizational Research Methods, 4: 324-349.

Cunningham, C. J. L., De La Rosa, G. M., \& Jex, S. M. 2008. The dynamic influence of individual characteristics on employee well-being: a review of the theory, research, and future directions. In J. Hellgren, M. Sverke, \& K. Näswall (Eds.), The individual in the changing working life: 258-283. New York: Cambridge University Press.

Falco, A., Girardi, D., Kravina, L., Trifiletti, E., Bartolucci, G. B., Capozza, D., \& De Carlo, N. A. 2013. The mediating role of psychophysic strain in the relationship between workaholism, 
job performance, and sickness absence: A longitudinal study. Journal of Occupational and Environmental Medicine, 55: 1255-1261.

Friedman, M., \& Rosenman, R. H. 1974. Type A behavior and your heart. New York, NY: Knopf.

Ganster D. C., \& Rosen, C. C. 2013. Work stress and employee health: A multidisciplinary review. Journal of Management, 39: 1085-1122.

Garst, H., Frese, M., \& Molenaar, P. C. M. 2000. The temporal factor of change in stressor-strain relationships: A growth curve model on a longitudinal study in East Germany. Journal of Applied Psychology, 85: 417-438.

Geurts S. A. E., \& Sonnentag, S. 2006. Recovery as an explanatory mechanism in the relation between acute stress reactions and chronic health impairment. Scandinavian Journal of Work, Environment \& Health, 32: 482-492.

Goldberg, D. P. 1972. The detection of psychiatric illness by questionnaire. Maudsley monograph N. 21. London: Oxford University Press.

Gosling, S. D., Rentfrow, P. J., \& Swann, W. B. 2003. A very brief measure of the Big-Five personality domains. Journal of Research in Personality, 37: 504-528.

Graham, J. W. 2009. Missing data analysis: making it work in the real world. Annual Review of Psychology, 60: 549-576.

Hakanen, J. J., Schaufeli, W. B., \& Ahola, K. 2008. The Job Demands-Resources model: A threeyear cross-lagged study of burnout, depression, commitment, and work engagement. Work \& Stress, 22: 224-241.

Hammer, L. B., Kossek, E. E., Yragui, N. L., Bodner, T. E., \& Hanson, G. C. 2009. Development and validation of a multidimensional measure of family supportive supervisor behaviors (FSSB). Journal of Management, 35: 837-856.

Harvey, A., Watkins, E., Mansell, W., \& Shafran, R. 2004. Cognitive behavioral processes across psychological disorders. Oxford. Oxford University Press. 
Häusser, J. A., Mojzisch, A., Niesel, M., \& Schulz-Hardt, S. (2010). Ten years on: A review of recent research on the Job Demand-Control (-Support) model and psychological well-being. Work \& Stress, 24, 1-35.

Hobfoll, S. E. 1989. Conservation of resources: A new attempt at conceptualizing stress. American Psychologist, 44 : 513-524.

Hobfoll, S. E. 2011. Conservation of resource caravans and engaged settings. Journal of Occupational and Organizational Psychology, 84: 116-122.

Holland, D. W. 2008. Work addiction: Costs and solutions for individuals, relationships and organizations. Journal of Workplace Behavioral Health, 22: 1-15.

Hu, L., \& Bentler, P. M. 1999. Cutoff criteria for fit indexes in covariance structure analysis: Conventional criteria versus new alternatives. Structural Equation Modeling, 6: 1-55.

Hu, Q., Schaufeli, W.B., Taris, T.W., van Hessen, D.J., Hakanen, J. Salanova, M., \& Shimazu, A. 2014. "East is East and West is West and never the twain shall meet": Work engagement and workaholism across Eastern and Western cultures. Journal Behavioral and Social Science, 1: 6-24.

Johnson, D. P., \& Whisman, M. A. 2013. Gender differences in rumination: A meta-analysis. Personality and Individual Differences, 55: 367-374.

Karasek, R., Brisson, C., Kawakami, N., Houtman, I., Bongers, P., \& Amick, B. 1998. The Job Content Questionnaire (JCQ): An instrument for internationally comparative assessments of psychosocial job characteristics. Journal of Occupational Health Psychology, 3: 322-355.

Kravina, L., Falco, A., De Carlo, N. A., Andreassen, C. S., \& Pallesen, S. 2014. Workaholism and work engagement in the family: The relationship between parents and children as a risk factor. European Journal of Work and Organizational Psychology, 23: 875-883. 
Kubota, K., Shimazu, A., Kawakami, N., Takahashi, M., Nakata, A., \& Schaufeli, W. B. 2010. Association between workaholism and sleep problems among hospital nurses. Industrial Health, 48: 864-871.

Landsbergis, P. 2004. Long work hours, hypertension, and cardiovascular disease. Cadernos de Saúde Pública, 20: 1746-1748.

Landsbergis, P., Schnall, P. L., Belkic, K. L., Baker, D., Schwartz, J. E., \& Pickering, T. G. 2003. The workplace and cardiovascular disease: relevance and potential role for occupational health psychology. In J. Q. Quick \& L. E. Tetrick (Eds.), Handbook of occupational health psychology: 265-287. Whashington, DC: American Psychological Association.

Lazarus, R. S. 2006. Stress and emotions: A new synthesis. New York: Springer.

Littman-Ovadia, H., Balducci, C., \& Ben-Moshe, T. 2013. Psychometric properties of the Hebrew version of the Dutch Work Addiction Scale (DUWAS-10). The Journal of Psychology: Interdisciplinary and Applied, 148: 327-346.

Lowman, R. L. 1993. Counseling and psychotherapy of work dysfunctions. Washington, DC: American Psychological Association.

Mazzetti, G. \& Schaufeli, W.B., \& Guglielmi, D. 2014. Are workaholics born or made? Relations of workaholism with person characteristics and overwork climate. International Journal of Stress Management, 21: 227-254.

McRae \& Weiss (2009). Observer ratings of personality. In R. W. Robins, R. C. Fraley, R. F. Krueger (eds.). Handbook of research methods in personality psychology (pp. 259-272)

Miller, R. B., \& Hollist, C. S. 2007. Attrition bias. In N. J. Salkind (Ed.), Encyclopedia of measurement and statistics (Vol. I). thousand Oaks, CA: Sage.

Morrison, N., \& Westbrook, D. 2004. Obsessive compulsive-disorder. In J. Bennet-Levy, G. Butler, M. Fennel, A. Hackmann, M. Mueller, \& D. Westbrook (Eds.), Oxford guide to behavioural experiments in cognitive therapy: 101-119. Oxford, UK: Oxford University press. 
Näswall, K., Hellgren, J., \& Sverke, M. 2008. The individual in the changing working life. New York: Cambridge University Press.

Ng, T. W. H., Sorensen, K. L., \& Feldman, D. C. 2007. Dimensions, antecedents, and consequences of workaholism: A conceptual integration and extension. Journal of Organizational Behavior, 28: $111-136$.

Oates, W. 1971. Confessions of a workaholic: The facts about work addiction. New York: World. Paustian-Underdahl, S., Halbesleben, J. R. B., Carlson, D. S., \& Kacmar, M. K. 2013. The workfamily interface and promotability: boundary integration as a double-edged sword. Journal of Management, doi: 10.1177/0149206313506464

Piccinelli, M., Bisoffi, G., Bon, M.G., Cunico, L., \& Tansella, M. 1993. Validity and test-retest reliability of the Italian version of the 12-item General Health Questionnaire in general practice: a comparison between three scoring methods. Comprehensive Psychiatry, 34: 198205.

Ployhart, R. E., \& Vandenberg, R. J. 2010. Longitudinal research: The theory, design, and analysis of change. Journal of Management, 36: 94-120.

Powell, G. N., \& Greenhaus, J. H. 2010. Sex, gender, and decisions at the family $\rightarrow$ work interface. Journal of Management, 36: 1011-1039.

Robinson, B. E. 1989. Work addiction. Deerfield beach, FL: Health Communications.

Robinson, B. E., \& Kelley, L. 1998. Adult children of workaholics: Self-concept, anxiety, depression, and locus of control. American Journal of Family Therapy, 26: 223-238.

Russo, M., Buonocore, F., Carmeli, A., \& Guo, L. 2015. When family supportive supervisors meet employees' need for caring: implications for work-family enrichment and thriving. Journal of Management, doi: 10.1177/0149206315618013 
Schaufeli, W. B., Bakker, A. B., van der Heijden, F. M. M. A., \& Prins, J. T. 2009. Workaholism, burnout, and well-being among junior doctors: The mediating role of role conflict. Work \& Stress, 23: 155-172.

Schaufeli, W. B., Shimazu, A., \& Taris, T. W. 2009. Being driven to work excessively hard: the evaluation of a two-factor measure of workaholism in the Netherlands and Japan. CrossCultural Research, 43: 320-348.

Schaufeli, W. B., Taris, T. W., \& Bakker, A. B. 2008. It takes two to tango: Workaholism is working excessively and working compulsively. In R. J. Burke \& C. L. Cooper (Eds.), The Long Work Hours Culture: Causes, consequences and Choices: 203-225. Bingley, UK: Emerald Group Publishing Limited.

Schaufeli, W. B., Taris, T. W., \& van Rhenen, W. 2008. Workaholism, burnout, and work engagement: Three of a kind or three different kinds of employee well-being? Applied Psychology: An International Review, 57: 173-203.

Schaufeli, W., \& van Rhenen, W. 2006. Over de rol van positieve en negatieve emoties bij het welbevinden van managers: Een studie met de Job-related Affective Well-being Scale (JAWS) [About the role of positive and negative emotions in managers' well-being: A study using the Job-related Affective Well-being Scale (JAWS)]. Gedrag und Organisatie, 19: 323-344.

Scott, K. S., Moore, K. S., \& Miceli, M. P. 1997. An exploration of the meaning and consequences of workaholism. Human Relations, 50: 287-314.

Shimazu, A., Demerouti, E., Bakker, A. B., Shimada, K., \& Kawakami, N. 2011. Workaholism and well-being among Japanese dual-earner couples: a spillover-crossover perspective. Social Science \& Medicine, 73: 399-409. 
Shimazu, A., Schaufeli, W. B., \& Taris, T. 2010. How does workaholism affect worker health and performance? The mediating role of coping. International Journal of Behavioral Medicine, 17: $154-160$.

Shirom A. 2003. Job-related burnout: A review. In J. Q. Quick \& L. E. Tetrick (Eds.), Handbook of occupational health psychology: 245-264. Washington, DC: American Psychological Association.

Siegrist, J. 1996. Adverse health effects of high-effort/low-reward conditions. Journal of Occupational Health Psychology, 1: 27-41.

Snir, R., \& Harpaz, I. 2012. Beyond workaholism: Towards a general model of heavy work investment. Human Resource Management Review, 22: 232-243.

Snir, R., \& Zohar, D. 2008. Workaholism as discretionary time investment at work: An experiencesampling study. Applied Psychology: An International Review, 57: 109-127.

Spence, J. T., \& Robbins, A. S. 1992. Workaholics: Definition, measurement, and preliminary results. Journal of Personality Assessment, 58: 160-178.

Sijtsma, K. 2009. On the use, the misuse, and the very limited usefulness of cronbach's alpha. Psychometrika, 74: 107-120.

Syrek, C. J., \& Antoni, C. H. 2014. Unfinished tasks foster rumination and impair sleeping Particularly if leaders have high performance expectations. Journal of Occupational Health Psychology, 19: 490-499.

Taris, T.W.. Van Beek, I. \& Schaufeli, W.B. 2014. The beauty versus the beast: On the motives of engaged and workaholic employees. In I. Harpaz and R. Snir (Eds), Heavy work investment: Its nature, sources, outcomes, and future directions: 121-138. New York: Taylor \& Francis/Routledge.

Taris. T., Van Beek, I., \& Schaufeli, W.B. 2012. Demographic and occupational correlates of workaholism. Psychological Reports, 110: 547-554. 
van Beek, I., Taris, T. W., \& Schaufeli, W. B. 2011. Workaholic and work engaged employees: Dead ringers or worlds apart? Journal of Occupational Health Psychology, 16: 468-482. Van Katwyk, P. T., Fox, S., Spector, P. E., \& Kelloway, E. K. 2000. Using the Job-related Affective Well-being Scale (JAWS) to investigate affective responses to work stressors. Journal of Occupational Health Psychology, 5: 219-230.

Warr, P. 2007. Work, happiness, and unhappiness. New York: Lawrence Erlbaum Associates.

Whaley, C.J., Morrison, D.L., Payne, R.L., Fritschi, L., \& Wall, T.D. 2005. Chronicity of psychological strain in occupational settings and the accuracy of the General Health Questionnaire. Journal of Occupational Health Psychology, 10: 310-319.

Widmer, P. S., Semmer, N. K., Kalin, W., Jacobshagen, N., \& Meier, L. L. 2012. The ambivalence of challenge stressors: Time pressure associated with both negative and positive well-being. Journal of Vocational Behavior, 80: 422-433.

Yang, H., Schnall, P. L., Jauregui, M., Su, T. C., \& Baker, D. 2006. Work hours and self-reported hypertension among working people in California. Hypertension, 48: 744-750.

Zapf, D., Dorman, C., \& Frese, M. 1996. Longitudinal studies in organizational stress research: A review of the literature with reference to methodological issues. Journal of Occupational Health Psychology, 1: 145-169. 


\section{FOOTNOTES}

${ }^{1}$ The positive association between workaholism and extraversion found by Clark et al. (2014) was explained by the authors by suggesting that certain facets of extraversion such as assertiveness may be related to workaholism.

${ }^{2}$ Clinical advisory statement by the National Institute of Health. Retrieved from https://www.nhlbi.nih.gov/health/prof/heart/hbp/hbpstmt/hbpstmt.htm

${ }^{3}$ LISREL makes available only the reported fit indices with FIML estimation. However, in our case these indices were sufficient for model assessment and hypotheses testing (see the Results and discussion section).

${ }^{4}$ Additional analyses in which we derived an overall measure of self-reported job-related affective well-being by combining positive and negative affective states revealed, in fact, that this measure was negatively related with workaholism, $r=-.19, \mathrm{p}<.01$. 


\section{TABLE 1}

Descriptive Statistics (Cronbach's Alpha in the Diagonal) and Intercorrelations Among Main Study 1 Variables

\begin{tabular}{|c|c|c|c|c|c|c|c|c|c|c|c|c|c|c|}
\hline Variable & $M$ & $S D$ & 1 & 2 & 3 & 4 & 5 & 6 & 7 & 8 & 9 & 10 & 11 & 12 \\
\hline 1- Workaholism & 2.45 & 0.50 & .77 & & & & & & & & & & & \\
\hline 2- Job-related negative affect (s-r $\left.{ }^{a}\right)$ & 2.40 & 0.94 & $.31 * * *$ & .83 & & & & & & & & & & \\
\hline 3- Job-related negative affective $\left(o-r^{b}\right)$ & 2.28 & 0.90 & $.17^{* *}$ & $.60 * * *$ & .82 & & & & & & & & & \\
\hline 4- Job-related positive affect (s-r) & 3.39 & 0.71 & .09 & $-.40 * * *$ & $-.40 * * *$ & .73 & & & & & & & & \\
\hline 5- Job-related positive affect (o-r) & 3.42 & 0.78 & -.02 & $-.40 * * *$ & $-.49 * * *$ & $.44 * * *$ & .76 & & & & & & & \\
\hline 7- Extraversion & 4.48 & 1.29 & .10 & $-.13 *$ & -.06 & $.18 * *$ & $.17^{* *}$ & .07 & .68 & & & & & \\
\hline 8- Systolic blood pressure & 121.45 & 12.30 & .09 & .00 & .01 & .01 & .14 & -.05 & -.05 & - & & & & \\
\hline 9- Gender ${ }^{\mathrm{c}}$ & 0.41 & 0.49 & .11 & .02 & -.01 & .01 & -.02 & $.19 * *$ & $.20 * *$ & $-.40 * * *$ & - & & & \\
\hline 10- Age (years) & 46 & 10 & -.01 & -.09 & .05 & .03 & .03 & -.05 & -.05 & $.21^{* *}$ & -.07 & - & & \\
\hline 11- Education ${ }^{\mathrm{d}}$ & 0.37 & 0.48 & .01 & .02 & .03 & .03 & -.03 & -.06 & -.06 & $-.17 *$ & .05 & -.04 & - & \\
\hline 13-Position_2 ${ }^{f}$ & 0.14 & 0.35 & $.12 *$ & -.04 & -.01 & .03 & .02 & -.09 & -.09 & -.02 & -.04 & $.12 *$ & $.17 * *$ & $.36 * *$ \\
\hline
\end{tabular}


Note. Correlations are based on a $N$ range of 297-311 with the exception of correlations including systolic blood pressure, which are

based on a $N$ range of $179-189 .{ }^{\mathrm{a}} \mathrm{s}-\mathrm{r}=$ self-reported; ${ }^{\mathrm{b}} \mathrm{o}-\mathrm{r}=$ observer reported; ${ }^{\mathrm{c}} 0=$ male, $1=$ female; ${ }^{\mathrm{d}} 0=$ up to high school diploma, 1

$=$ university degree or higher; ${ }^{\mathrm{e}} 0=$ other, $1=$ self-employed/entrepreneur; ${ }^{\mathrm{f}} 0=$ other, $1=$ manager.

$* p<.05$

${ }_{* *} p<.01$

${ }^{* * *} p<.001$ 


\section{TABLE 2}

Hierarchical Regression Analysis Predicting Self-Reported Job-Related Negative Affect in Study 1 $(\mathrm{N}=311)$ : Pooled Estimates Resulting from Multiple Imputation.

\begin{tabular}{|c|c|c|c|c|}
\hline & Step $1 B(S E)$ & Step $2 B(S E)$ & Step $3 B(S E)$ & Step $4 B(S E)$ \\
\hline Constant & $2.75(0.27)^{* * *}$ & $2.29(0.33)^{* * *}$ & $2.51(0.32)^{* *}$ & $2.50(0.32) *$ \\
\hline Gender $^{\mathrm{a}}$ & $-0.01(0.11)$ & $-0.08(0.11)$ & $-0.13(0.10)$ & $-0.14(0.10)$ \\
\hline Age & $-0.01(0.01)$ & $-0.01(0.01)$ & $-0.01(0.01)$ & $-0.01(0.01)$ \\
\hline Education $^{\mathrm{b}}$ & $0.06(0.11)$ & $0.07(0.10)$ & $0.08(0.10)$ & $0.08(0.10)^{*}$ \\
\hline Position_ $1^{\mathrm{c}}$ & $-0.16(0.12)$ & $-0.19(0.11)$ & $-0.25(0.11) *$ & $-0.26(0.11) *$ \\
\hline Position_2 $2^{d}$ & $-0.19(0.17)$ & $-0.16(0.16)$ & $-0.30(0.15) *$ & $-0.32(0.15)^{* * *}$ \\
\hline Neuroticism & & $0.29(0.04)^{* * *}$ & $0.25(0.04)^{* * *}$ & $0.25(0.04)^{* *}$ \\
\hline Extraversion & & $-0.12(0.04)^{* *}$ & $-0.13(0.04)^{* *}$ & $-0.12(0.04)^{* *}$ \\
\hline Workaholism & & & $0.27(0.05)^{* * *}$ & $0.18(0.07) *$ \\
\hline $\begin{array}{l}\text { Workaholism X } \\
\text { Gender }\end{array}$ & & & & $0.19(0.10)^{*}$ \\
\hline$\Delta R^{2}$ & .015 & $.158^{* * *}$ & $.077 * * *$ & $.010 *$ \\
\hline
\end{tabular}

Note. Unstandardized pooled regression coefficients and average $\Delta R^{2}$ across the 50 multiple imputations of missing data are reported. ${ }^{\mathrm{a}} 0=$ male, $1=$ female; ${ }^{\mathrm{b}} 0=$ up to high school diploma, 1 $=$ university degree or higher; ${ }^{\mathrm{c}} 0=$ other, $1=$ self-employed/entrepreneur; ${ }^{\mathrm{d}} 0=$ other, $1=$ manager.

$* p<.05$

$* * p<.01$

$* * * p<.001$ 


\section{TABLE 3}

Hierarchical Regression Analysis Predicting Observer-Reported Job-Related Negative Affect in Study 1 (N=311): Pooled Estimates Resulting from Multiple Imputation.

\begin{tabular}{|c|c|c|c|c|}
\hline & Step $1 B(S E)$ & Step $2 B(S E)$ & Step $3 B(S E)$ & Step $4 B(S E)$ \\
\hline Constant & $2.18(0.26)^{* * *}$ & $1.38(0.32) * * *$ & $0.88(0.37) *$ & $1.60(0.42)^{* *}$ \\
\hline Gender $^{\mathrm{a}}$ & $-0.05(0.11)$ & $-0.16(0.10)$ & $-0.19(0.10)$ & $-1.07(0.48) *$ \\
\hline Age & $0.01(0.01)$ & $0.01(0.01)$ & $0.01(0.01)$ & $0.01(0.01)$ \\
\hline Education $^{b}$ & $0.11(0.11)$ & $0.14(0.10)$ & $0.16(0.10)$ & $0.14(0.10)$ \\
\hline Position_ $1^{\mathrm{c}}$ & $-0.09(0.12)$ & $-0.14(0.11)$ & $-0.15(0.11)$ & $-0.17(0.11)$ \\
\hline Position_2 ${ }^{\mathrm{d}}$ & $-0.12(0.16)$ & $-0.08(0.15)$ & $-0.14(0.15)$ & $-0.16(0.15)$ \\
\hline $\begin{array}{l}\text { Relationship with } \\
\text { participant }^{\mathrm{e}}\end{array}$ & $-0.32(0.13)^{*}$ & $-0.26(0.12) *$ & $-0.30(0.12)^{*}$ & $-0.29(0.12) *$ \\
\hline Neuroticism & & $0.28(0.04)^{* * *}$ & $0.26(0.04)^{* * *}$ & $0.26(0.04)^{* * *}$ \\
\hline Extraversion & & $-0.04(0.04)$ & $-0.05(0.04)$ & $-0.04(0.04)$ \\
\hline Workaholism & & & $0.26(0.10)^{* *}$ & $0.09(0.13)$ \\
\hline $\begin{array}{l}\text { Workaholism X } \\
\text { Gender }\end{array}$ & & & & $0.36(0.19)^{p=.059}$ \\
\hline$\Delta R^{2}$ & .027 & $.147 * * *$ & $.019^{* *}$ & $.010^{p=.059}$ \\
\hline
\end{tabular}

Note. Unstandardized pooled regression coefficients and average $\Delta R^{2}$ across the 50 multiple imputations of missing data are reported. ${ }^{\mathrm{a}} 0=$ male, $1=$ female; ${ }^{\mathrm{b}} 0=$ up to high school diploma, 1 $=$ university degree or higher; ${ }^{\mathrm{c}} 0=$ other, $1=$ self-employed/entrepreneur; ${ }^{\mathrm{d}} 0=$ other, $1=$ manager; ${ }^{\mathrm{e}} 0=$ partner/cohabitant family member, 1 = colleague/collaborator.

$* p<.05$ 
$* * p<.01$

$* * * p<.001$ 


\section{TABLE 4}

Hierarchical Regression Analysis Predicting Systolic Blood Pressure in Study 1 (N=189): Pooled Estimates Resulting from Multiple Imputation.

\begin{tabular}{|c|c|c|c|c|}
\hline & Step $1 B(S E)$ & Step $2 B(S E)$ & Step $3 B(S E)$ & Step $4 B(S E)$ \\
\hline Constant & $115.51(4.11)^{* * *}$ & $114.44(5.85)^{* * *}$ & $116.58(5.91)^{* * *}$ & $116.41(5.94)^{* * *}$ \\
\hline Gender $^{\mathrm{a}}$ & $-8.74(1.72)^{* * *}$ & $-8.86(1.79)^{* * *}$ & $-9.39(1.80) * * *$ & $-9.37(1.80)^{* * *}$ \\
\hline Age & $0.23(0.09)^{* *}$ & $0.23(0.09)^{* *}$ & $0.23(0.09)^{* *}$ & $0.23(0.09)^{* *}$ \\
\hline Education $^{\mathrm{b}}$ & $-2.67(1.77)$ & $-2.64(1.78)$ & $-2.68(1.77)$ & $-2.62(1.78)$ \\
\hline Position_1 ${ }^{\mathrm{c}}$ & $1.79(1.86)$ & $1.73(1.88)$ & $1.08(1.90)$ & $1.11(1.90)$ \\
\hline Position_2 $2^{\mathrm{d}}$ & $0.92(2.71)$ & $0.90(2.72)$ & $0.14(2.73)$ & $0.19(2.74)$ \\
\hline Neuroticism & & $0.13(0.69)$ & $-0.18(0.71)$ & $-0.15(0.71)$ \\
\hline Extraversion & & $0.13(0.67)$ & $0.02(0.68)$ & $-0.01(0.68)$ \\
\hline Workaholism & & & $1.74(0.87) *$ & $2.07(1.17)$ \\
\hline $\begin{array}{l}\text { Workaholism X } \\
\text { Gender }\end{array}$ & & & & $-0.72(1.70)$ \\
\hline$\Delta R^{2}$ & $.208^{* * *}$ & .001 & $.018 *$ & .001 \\
\hline
\end{tabular}

Note. Unstandardized pooled regression coefficients and average $\Delta R^{2}$ across the 50 multiple imputations of missing data are reported. ${ }^{\mathrm{a}} 0=$ male, $1=$ female $;{ }^{\mathrm{b}} 0=$ up to high school diploma, 1 $=$ university degree or higher; ${ }^{\mathrm{c}} 0=$ other, $1=$ self-employed/entrepreneur; ${ }^{\mathrm{d}} 0=$ other, $1=$ manager.

$* p<.05$

$* * p<.01$

$* * * p<.001$ 
TABLE 5

Descriptive Statistics and Intercorrelations Among Main Study 2 Variables . Cronbach's Alpha in the Diagonal.

\begin{tabular}{|c|c|c|c|c|c|c|c|c|c|}
\hline Variable & $M$ & $S D$ & 1 & 2 & 3 & 4 & 5 & 6 & 7 \\
\hline 1- T1 Workaholism & 2.09 & 0.50 & .79 & & & & & & \\
\hline 2- T2 Workaholism & 2.13 & 0.51 & $.56^{* * *}$ & .80 & & & & & \\
\hline 3- T1 Job demands & 2.89 & 0.42 & $.32 * * *$ & $.32 * * *$ & .68 & & & & \\
\hline 4- T2 Job demands & 2.87 & 0.45 & $.17 *$ & $.41 * * *$ & $.54 * * *$ & .70 & & & \\
\hline 5- T1 Psychological distress & 3.56 & 2.46 & $.35^{* * *}$ & $.27 * * *$ & $.26^{* * *}$ & $.18^{*}$ & .82 & & \\
\hline 6- T2 Psychological distress & 3.74 & 2.74 & $.28^{* * *}$ & $.38^{* * *}$ & $.20^{* *}$ & $.23 * *$ & $.50 * * *$ & .86 & \\
\hline 7- Gender $^{\mathrm{a}}$ & 0.42 & 0.49 & -.01 & .01 & .02 & -.10 & .12 & $.16 *$ & - \\
\hline
\end{tabular}

Note. Correlations are based on a $N$ range of $192-232 .{ }^{a} 0=$ male, $1=$ female.

$$
\begin{aligned}
& * p<.05 \\
& * * p<.01 \\
& * * * p<.001
\end{aligned}
$$




\section{FIGURE 1}

The Moderating Role of Gender in the Relationship Between Workaholism and Self-Reported Job-Related Negative Affect (Study 1).

Job-Related Negative Affect

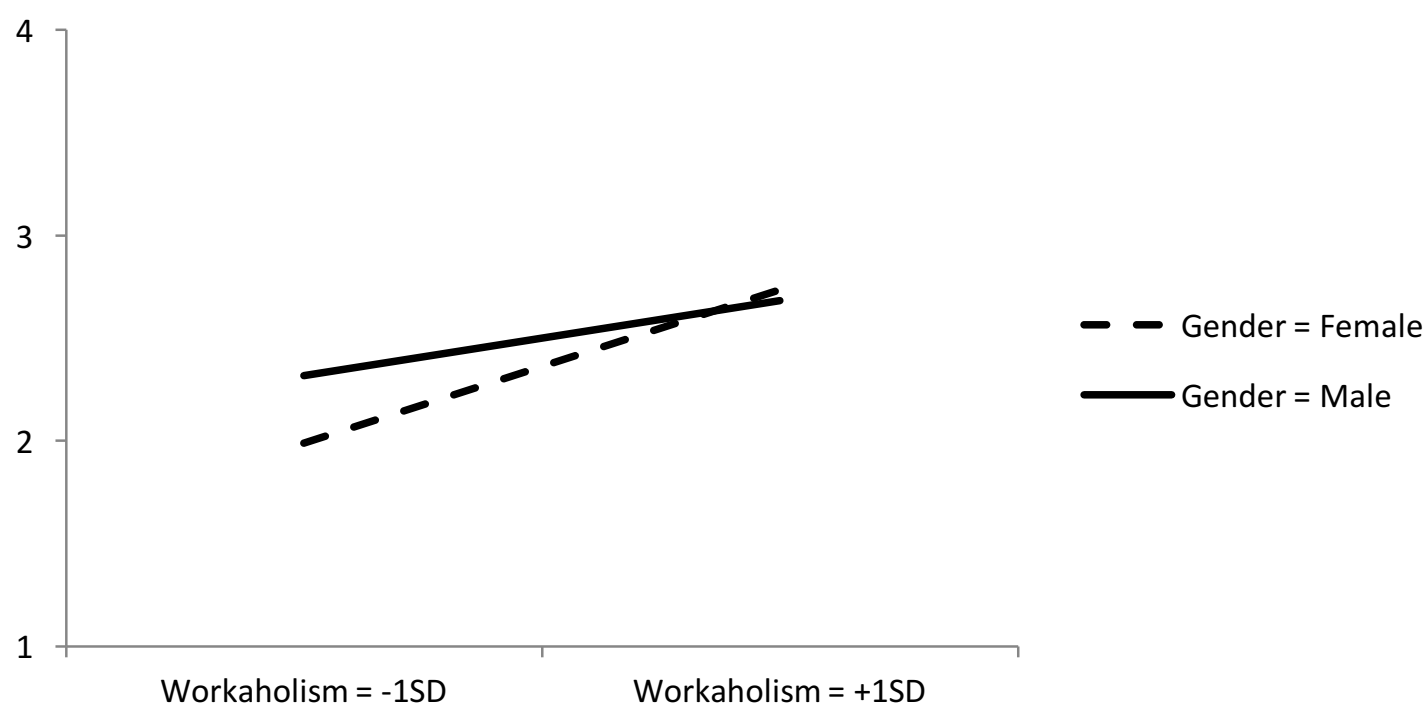




\section{FIGURE 2}

Path Analytic Model Testing for the Cross-Lagged Relationship Between Workaholism, Mental Distress and Job Demands in Study 2 (N=235). Standardized Coefficients Are Reported in Paths.

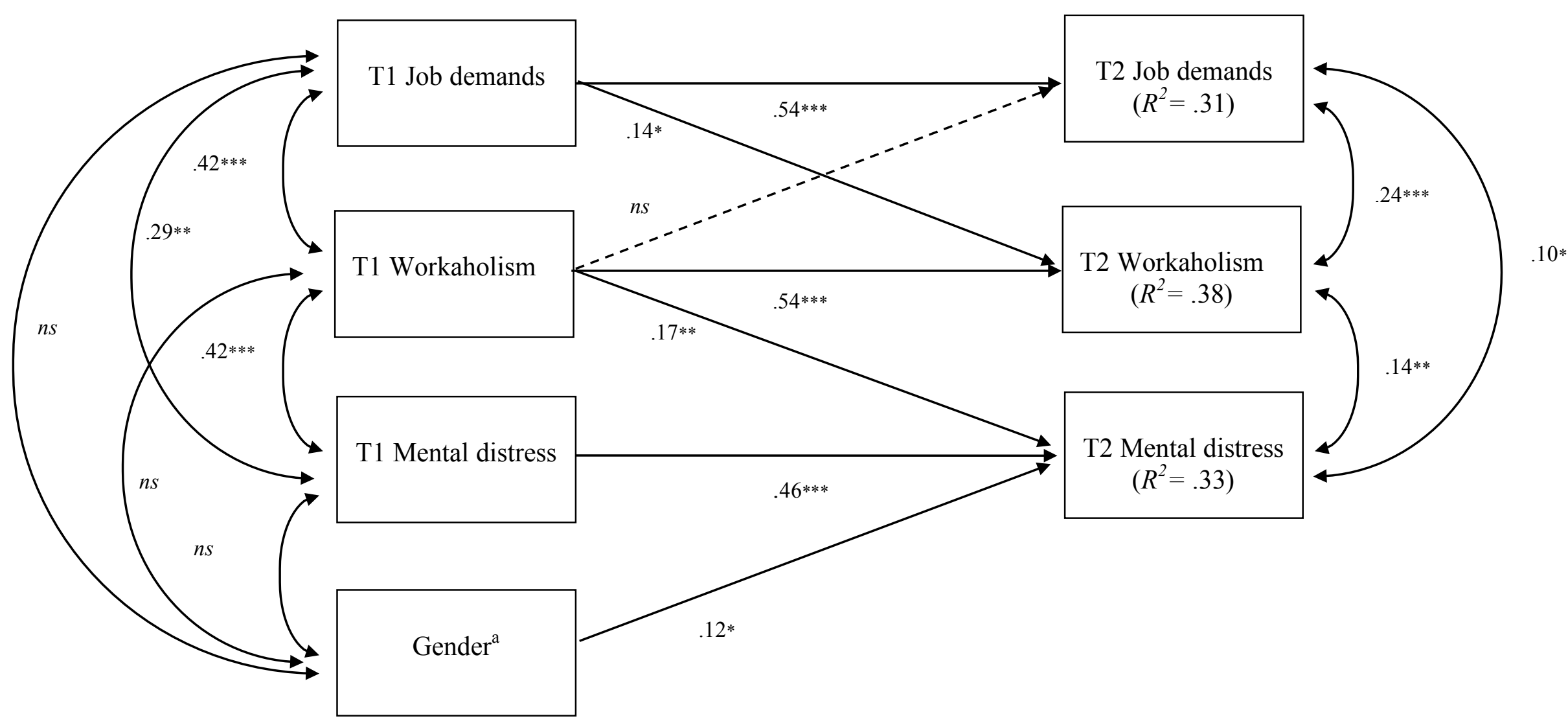


Note. ${ }^{\mathrm{a}} 0=$ male, $1=$ female

$* p<.05$

$* * p<.01$

$* * * p<.001$ 